\title{
0501 TARGETING SAFETY IN POLICY MAKING: MENTAL HEALTH RISKS IN ASYLUM SEEKERS
}

F U Kärki*, H Bie Correspondence: Norwegian Directorate of Health, Universitetsgata 27000 Street, Olavsplass N-0130 Oslo N-0130, Norway

\subsection{6/ip.2010.029215.501}

In 2009, Norway received 17170 asylum seekers from a number of countries, a majority coming from Afghanistan, Eritrea, Somalia and Iraq. The amount of asylum seekers doubled from 2007 to 2008 . Traumatic factors related to life situation prior to migration and different phases in the migration process lead to increased vulnerability for severe psychiatric problems and disorders in this population, representing a safety issue the Norwegian Government seeks to meet through different policy actions. The most frequent diagnoses are post traumatic stress disorder (PTSD) and depressive/anxiety disorders. A meta-analysis demonstrates that the incidence of PTSD in asylum seekers from formerly conflict-ridden regions is relatively high, varying between $15-47 \%$ against an estimated $1.3-8 \%$ in the rest of the population in the USA and Australia (Silove, 2004). In recent years the interaction between traumatic past experiences and increased risk for violent acts has been put on the agenda, demanding joint strategies from different sectors such as health, justice and foreign affairs. The need for screening to identify mental health problems requiring immediate attention has been highlighted as an important measure, together with capacity and competence building among healthcare professionals, social services and staff in reception centres. Substantial inter-ministerial investments have been made resulting in a number of projects targeting mental health risks in asylum seekers and risk behaviour in reception centres. In addition somatic and mental health of asylum seekers is one of the main specialties in five newly established regional centres for violence, traumatic stress and suicide prevention. 